\title{
CAPÍTULO 14: A IMINÊNCIA DO ENSINO DE LIBRAS PARA OUVINTES: KNOW-HOW DE UM ESTÁGIO SUPERVISIONADO EM LIBRAS
}

\section{CAPÍTULO 14: LA INMINENCIA DE LIBRAS ENSEÑANZA PARA OYENTES: SABER HACER DE UNA ETAPA SUPERVISADA EN LIBRAS}

\section{CHAPTER 14: THE IMMINENCE OF LIBRAS TEACHING FOR LISTENERS: KNOW-HOW OF A SUPERVISED STAGE IN LIBRAS}

Jaqueline Costa da Silva Lima ${ }^{1}$; Lúcio Costa de Andrade $^{2}$; José Roniero Diodato ${ }^{3}$; Adriana Patrícia da Silva ${ }^{4}$, Antônio Carlos Cardoso 5

DOI: https://doi.org/10.31692/978-65-88970-05-8.199-204

\section{INTRODUÇÃO}

O debate sobre a questão da inclusão social possibilita reflexões sobre a inclusão educacional, tema que tem provocado discussões nas últimas décadas, pois se acredita que por meio da educação se alcança a inclusão social. Sendo assim, com base na literatura de Fernandes (2008) e Gesser (2010), dentre outros, neste estágio buscamos conhecer o trabalho realizado na sala de atendimento educacional especializado quanto ao incentivo e oferta de atividades de ensino de língua brasileira de sinais como L2 para ouvintes, o que facilita significativamente o processo de acessibilidade comunicacional, interação qualitativa e de inclusão escolar.

Reiteramos, pois, que após o know-how da observação da prática pedagógica na escola campo de estágio, percebemos que alguns alunos ouvintes demonstravam interesse em aprender a libras para se comunicar com os colegas surdos. Assim, para promover o engajamento dos alunos nas atividades propostas, decidimos convidar alunos surdos e alunos ouvintes que já tinham bom conhecimento da libras para atuarem como monitores nas aulas propostas, cujo formato foi de oficina.

Dessa forma, fica evidente a necessidade de acordamos com as professoras da sala de atendimento educacional especializado a melhor estratégia para tornar o aluno protagonista do processo formativo, e ainda sobre um método que possa promover o desenvolvimento de habilidades que estão no escopo do letramento linguístico, neste caso da L2 (libras para alunos

\footnotetext{
${ }^{1}$ Pedagoga, Graduanda em Letras Libras, pelo Centro Universitário Leonardo Da Vinci/UNIASSELVI, Especialista em Psicopedagogia Clínica pela UNIFACOL e Proficiência em Tradução e Interpretaçã̃o da Libras pela ALPHA, jaqueline.costal@ufpe.br

${ }_{2}^{2}$ Pedagogo, Graduando em Letras Libras, Universidade Federal da Paraíba/UFPB, lucio.costa@ac

${ }^{3}$ Pedagogo, Graduando em Letras Libras, Universidade Federal de Pernambuco/UFPE, roniero.diodato@ufpe.br

${ }^{4}$ Pedagoga, Graduanda em Letras Libras, pelo Centro Universitário Leonardo Da Vinci/UNIASSELVI, dry.patricia@hotmail.com

${ }^{5}$ Mestrando em Educação pelo Programa Pós-graduação em Educação - PPGEdu da UFPE, Especialista em Língua Brasileira de Sinais pela Universidade Salgado de Oliveira - UNIVERSO, antonio.ccardoso@ufpe.br
} 
ouvintes).

\title{
FUNDAMENTAÇÃO TEÓRICA
}

Para aprofundarmos a compreensão desse tema que registra o know-how das atividades realizadas na disciplina de o estágio curricular obrigatório II, escolhemos como área de concentração: Educação Inclusiva/ Libras porque se trata de um fator iminente sobre as questões pedagógicas inseridas no processo de ensino aprendizagem de alunos surdos e ouvintes. E nos cabe a competência, enquanto licenciados em processo de formação educacional, buscarmos experiência profissional como afirma o autor Le Boterf, (1995):

\begin{abstract}
A competência do indivíduo não é um estado, não se reduz a um conhecimento ou know how específico. Situa a competência numa encruzilhada, com três eixos formados pela pessoa (sua biografia, socialização), pela sua formação educacional e pela sua experiência profissional. A competência é o conjunto de aprendizagens sociais e comunicacionais nutridas a montante pela aprendizagem e formação e a jusante pelo sistema de avaliações. Segundo ainda este autor: competência é um saber agir responsável e que é reconhecido pelos outros. Implica saber como mobilizar, integrar e transferir os conhecimentos, recursos e habilidades, num contexto profissional determinado.
\end{abstract}

Nesse sentido, essa competência de saber como mobilizar, integrar e transferir os conhecimentos, recursos e habilidades. Permite que o conhecimento da temática, e assim perceber que o ensino da Língua Brasileira de Sinais- LIBRAS como L2 para alunos ouvintes é urgente e ainda em uma escola pública é algo inovador. Com o intuito de proporcionar um ambiente inclusivo na educação, todos os integrantes da escola deveriam aprender Libras. Contudo, apesar dos muitos avanços e das conquistas da comunidade surda a Lei 10.436/02, determina que:

Art. $4^{\circ} \mathrm{O}$ sistema educacional federal e os sistemas educacionais estaduais, municipais e do Distrito Federal devem garantir a inclusão nos cursos de formação de Educação Especial, de Fonoaudiologia e de Magistério, em seus níveis médio e superior, do ensino da Língua Brasileira de Sinais - Libras, como parte integrante dos Parâmetros Curriculares Nacionais - PCNs, conforme legislação vigente.

Isto é, a Lei determina que o ensino de Libras seja obrigatório nos cursos de nível superior, não incluindo assim a educação infantil e o ensino fundamental, que seria um grande avanço e eliminaria as barreiras comunicacionais entre alunos surdos e ouvintes.

Nesse sentido, corroboramos com Barbosa e Lacerda (2019) quando dizem que: "Reconhecemos que a oferta da Libras para as crianças ouvintes como segunda língua é importante para o processo de inclusão do estudante ouvinte, mas esta situação não deveria ser uma exceção, ou melhor, uma gentil concessão da escola", no entanto, esta disciplina ainda não faz parte do currículo obrigatório e as vivências se dão quando a escola assume a inclusão como 
sua filosofia e prática.

Nos vários cenários que configuram a escola, a sala de aula, os horários de intervalos, os horários de atendimento individualizado na sala de recursos multifuncionais há, na interação entre surdos e ouvintes, com frequência significativa, uma intencionalidade em aprender uma língua que torne possível a intervenção sem barreiras comunicacionais. Esse itinerário é marcado por tensões, por questões sócio discursivas, político-ideológicas, culturais e metodológicas (GESSER, 2010; OLIVEIRA, 2006; STROBEL, 2009).

Ademais, através do trabalho de letramento na L2 os alunos ouvintes tendem a perceber que o surdo é, por assim dizer, um indivíduo histórico que escreve e se inscreve na história através das experiências visuais. Isso se dá porque, de acordo com Perlin (2015), a maneira de pensar e de se expressar do surdo é diferente do modo de ser do ouvinte. Essa compreensão da diferença é essencial para que o professor pense em estratégias que motivem os alunos surdos e mostrem aos alunos ouvintes o quanto o aspecto visual é importante para a comunidade surda.

\section{METODOLOGIA}

O know-how da disciplina de estágio curricular obrigatório II, nos permitiu o aprofundamento das questões pedagógicas inseridas no processo de ensino aprendizagem de alunos surdos e ouvintes, as quais foram vivenciadas numa escola municipal de Vitória de Santo Antão- PE, no período de fevereiro a março de 2020 na sala de Atendimento Educacional Especializado-AEE.

Durante o estágio, realizamos observações no âmbito escolar e da prática pedagógica com alunos surdos, na sala de atendimento educacional especializado. Também observamos as interações dos alunos durante os horários de recreio e nos intervalos, alguns ouvintes buscavam interagir com os surdos. Havia muita harmonia entre os docentes do AEE, os professores intérpretes, alguns docentes que atuam na sala regular e os estudantes.

No entanto, é preciso destacar que a escola não dispõe de intérprete para atuar exclusivamente na sala de recursos e as professoras estão aprendendo libras. Assim, mesmo contando com a gentileza, a boa vontade e a colaboração dos interpretes há dificuldades na realização do atendimento. As dificuldades também envolvem a baixa frequência dos alunos, quando o trabalho é ofertado no contra turno.

O público alvo, alunos dos anos finais do ensino fundamental atendidos no AEE, na faixa etária dos 13-16 anos, demonstrou grande interesse pelas atividades propostas e pelos recursos que incluíam o aspecto visual, o lúdico. Para alcançar os objetivos propostos os 12 
alunos e os 6 monitores interagiram eficientemente trocando saberes, tanto os surdos puderam ensinar um pouco de sua língua aos alunos ouvintes, quanto também revisitaram e aprenderam sinais conosco, principalmente referentes a variações linguísticas de conteúdos organizados da seguinte forma:

- $\quad \mathbf{1}^{\text {a }}$ Oficina: Conceito de Libras; Lei no 10.436/2002 e O Surdo na História;

- $\quad 2^{a}$ Oficina: Alfabeto Manual; Números e Cores;

- $\quad 3^{a}$ Oficina: Sinais de Materiais Escolar e Sinais de Animais;

- $\quad$ 4a Oficina: Vocabulário Básico com 20 Palavras;

- $\quad 5^{\mathrm{a}}$ Oficina: Pequenos Diálogos.

Como recursos, utilizamos jogos que reúnem o sinal, a palavra em português, a datilologia e o desenho, também utilizamos pequenas animações sobre os assuntos abordados: alfabeto manual, numerais, cumprimentos, materiais escolares e espaços escolares e vocábulo especifico de acordo com a curiosidade dos participantes ou o momento da aula.

\section{RESULTADOS E DISCUSSÃO}

Com base nos dados vivênciados, destacamos que as docentes não tem domínio da libras e para sanar essa dificuldade já solicitaram um profissional com proficiência que compusesse a equipe, mas até agora a secretaria de educação da cidade não apresentou resposta sobre este suporte. Enquanto isso, a gestão da escola juntamente a coordenação do AEE busca alternativas para atender ao aluno surdo e garantir a sua inclusão por meio da acessibilidade comunicacional com os demais estudantes que demonstram interesse pela libras.

Isso demonstra, todo o esforço da escola em atender os alunos de acordo com o que apregoa a filosofia da inclusão e eliminar barreiras de diferentes dimensões que presume: quebras de barreiras arquitetônicas, atitudinais, comunicacional. Temos, então, observado que o ensino de libras como L2 para ouvintes é iminente e favorece a manutenção de uma escola inclusiva, valoriza a cultura surda, fortalece a identidade surda e ainda motiva a dinâmica de um ambiente respeitoso à diversidade humana.

Os alunos ouvintes demonstraram alegria em aprender e na realização dos jogos cada aluno surdo era o "padrinho" de um grupo de ouvintes, aprendiam se divertindo, se instalou uma competição boa, lúdica em algumas atividades. Os alunos ouvintes também compreenderam um pouco sobre a cultura surda e receberam nome sinal, pois nem todos tinham. Vale reiterar, que o ensino de uma língua como L2, neste caso a Libras, que é uma língua visuoespacial e para o aluno ouvinte serão necessárias competências que envolvem tanto 
a visão para compreender o gestual da linguagem quanto à oralização do significado dos sinais (GESSER, 2020; ISIDORO, 2017).

Ainda, convém destacar a importância da abordagem do ensino da Libras como L2 para ouvinte no planejamento de estágio, visto que propiciou nas oficinas uma dinâmica de interação comunicativa entre os alunos surdos e ouvintes demostrando que é possível e de fato acontecer um processo educativo inclusivo na perspectiva de acessibilidade comunicacional, e assim fortalecer o status linguístico e cultural da Libras e da comunidade surda.

\section{CONCLUSÕES}

Levando em consideração os conhecimentos vivenciados nessa pesquisa, ficou claro que cabe à instituição escolar propor dentro do seu PPP - Projeto Político Pedagógico uma proposta pedagógica que promova a acessibilidade comunicacional de seus alunos surdos, visto que estar em lei considerar as singularidades linguísticas desses sujeitos e que dessa forma possibilitar um ambiente de convivência com igualdade para todos.

É notório que, trabalhar com o ensino de L2 para alunos ouvintes é, por assim dizer, fortalecer a acessibilidade atitudinal e comunicacional as quais estão no coração/ na centralidade de um processo inclusivo verdadeiro. Assim, percebemos que alguns alunos pensavam que Libras envolvia mímica, pois eles disseram que não sabiam que libras tinha gramática própria e é considerada uma língua viva.

Por isso, as oficinas de libras proporcionou aos alunos ouvintes uma interação maior com os surdos e toda comunidade surda inserida na escola, no qual grande parte tiveram a oportunidade de se comunicar sem barreiras e tornando os espaços mais acessíveis as pessoas surdas. Ou seja, o ensino da Libras para ouvintes não é simplesmente ensinar uma nova língua, mas sim incluir as pessoas surdas no convívio social sem que haja diferenças.

Dessa forma, aprender a Língua de Brasileira de Sinais-Libras na prática por meio dessas oficinas tornou ainda mais fácil o aprendizado da língua e assim, abordar diretamente a inclusão de alunos surdos no ensino regular mostrando que é possível uma inclusão sem discriminação.

Logo, mediante o exposto de que todas essas vivências comprovaram a respeito do papel da escola, enquanto instituição responsável por formar cidadãos proativos socialmente, é alcançado quando existem as acessibilidades: atitudinal, comunicacional, metodológica e a instrumental, no caso do atendimento ao aluno surdo assegurando-o a um processo de aprendizagem verdadeiramente inclusivo. 
Em vista disso, a nossa esperança é a de que algum dia a Libras se torne disciplina obrigatória na educação básica, o bilinguismo se instale, a pedagogia visual seja vivenciada fortalecida e o surdo tenha vez e voz nas ciências, na vida, no mundo e que essa experiência seja fonte para outras discussões relacionadas ao ensino da Libras para educação inclusiva dos alunos surdos, bem como o levantamento de novos estudos nessa temática.

\section{REFERÊNCIAS}

BARBOSA, Ana Clarisse Alencar; LACERDA, Lúcia Loreto. Parâmetros de ensino em língua Brasileira de sinais como L2. UNIASSELVI, 2019.

BRASIL. Lei n. 10.436, de 24 de abril de 2002. Dispõe sobre a Língua Brasileira de Sinais LIBRAS e dá outras providências. Brasília, 2002.

FERNANDES, Eulália (Org.) Surdez e bilinguismo. Porto Alegre: Mediação, 2008.

GESSER, Audrei. Metodologia de Ensino em LIBRAS como L2. Universidade Federal de Santa Catarina Licenciatura e Bacharelado em Letras-Libras. Florianópolis 2010. Disponível em<http://www.libras.ufsc.br/colecaoLetrasLibras/eixoFormacaoPedagogico/metodologiaDe EnsinoEmLibrasComoL2/assets/629/TEXTOBASE_MEN_L2.pdf > Acesso em 02 de jun. 2020.

ISIDORIO, Allisson Roberto. Inclusão: aulas de Libras (L2) para crianças ouvintes em uma escola inclusiva no Programa Mais Educação. Revista de Cultura Surda, Editora Arara Azul, no 20, jan. 2016. Disponível em: http://editora-arara-azul.com.br/site/revista_edicoes. Acesso em 14 out. 2016.

LE BOTERF, G. De la compétence - essai sur un attracteur étrange. In: Les éditions d'organisations. Paris: Quatrième Tirage, 1995.

OLIVEIRA, Fabiana Barros. Desafios na inclusão dos surdos e o intérprete de Libras. Diálogos \& Saberes, Mandaguari, v. 8, nº 1, p. 93-108, 2006.

PERLIN. G. Identidades Surdas. In: A surdez: um olhar sobre as diferenças. - 7. Ed. - Porto Alegre: Mediação, 2015.

STROBEL, Karin. As imagens do outro sobre a cultura surda. Florianópolis: 2009. 